\title{
Hyperventilation and asymptomatic chronic asthma
}

\author{
C A Osborne, B J O’Connor, A Lewis, V Kanabar, W N Gardner
}

\begin{abstract}
Background-We have consistently argued that mild asthma is an important underlying aetiological factor in patients with severe symptomatic hyperventilation. While hyperventilation has been demonstrated in acute asthma, there have been few studies in mild chronic asthma, and mechanisms are uncertain.

Methods-Twenty three currently asymptomatic chronically asthmatic patients (occasional use of bronchodilators, normal lung function, hyperresponsive to methacholine) were studied and 17 matched normal subjects acted as controls. Ventilation, pattern of breathing, arterial carbon dioxide and oxygen tensions $\left(\mathrm{PaCO}_{2}, \mathrm{PaO}_{2}\right)$, end tidal $\mathrm{PCO}_{2}$ $\left(\right.$ PeTCO $\left._{2}\right)$, standard lung function, airway responsiveness to methacholine, airway inflammation assessed by eosinophils in induced sputum, and psychiatric morbidity (Spielberger STAI-Y and Beck Depression Inventory) were measured.
\end{abstract}

Results-Despite the absence of current asthmatic symptoms, no clinical evidence of hyperventilation, and normal lung function in the patients with asthma, $\mathbf{P a C O}_{2}$ and $\mathrm{PeTCO}_{2}$ were significantly $(p<0.01)$ lower in the patients than in the control group (mean (SD) $\mathrm{PaCO}_{2} 4.96$ (0.43) $\mathrm{kPa}$ for patients versus $\mathbf{5 . 2 7}$ (0.38) $\mathrm{kPa}$ for controls (mean difference $0.31 \mathrm{kPa}, 95 \%$ confidence interval (CI) 0.06 to $0.56, p<0.02)$ ). Petco $_{2}$ was very similar to $\mathrm{PaCO}_{2}$ in both groups (mean (SD) $\mathrm{PeTCO}_{2} 4.89(0.47) \mathrm{kPa}$ for the patients and $5.28(0.40)$ for the controls (mean difference $0.39 \mathrm{kPa}, 95 \%$ CI 0.12 to $0.66, p<0.01)$ ). There was no significant difference in ventilation or respiratory pattern between the two groups. The reduced $\mathrm{PaCO}_{2}$ in the asthmatic patients correlated significantly with the concentration of methacholine provoking a fall in FEV $_{1}$ of more than $20 \%\left(\mathrm{PC}_{20}\right)(r=0.56$, $\mathbf{p}<0.01$ ) but not with any aspect of lung function, eosinophil count, or anxiety/ depression.

Conclusion-Mild asymptomatic asthma is not associated with clinically significant hyperventilation but is associated with a significant reduction in both arterial and end tidal $\mathrm{PCO}_{2}$ which relates to airway hyperresponsiveness rather than to the degree of airway obstruction or mucosal inflammation. Anxiety and depression appear not to be implicated.

(Thorax 2000;55:1016-1022)
Keywords: breathing pattern; hypocapnia; carbon dioxide; hyperventilation syndrome; asthma

Hyperventilation is well recognised as a concomitant of acute asthma, and studies in which arterial carbon dioxide tension $\left(\mathrm{PaCO}_{2}\right)$ was related to the severity of acute asthma show clear evidence of significant hyperventilation with only modest reductions in forced expiratory volume in one second $\left(\mathrm{FEV}_{1}\right){ }^{1}$

The mechanisms of hyperventilation in asthma remain uncertain. ${ }^{2}$ Increased respiratory drive may be caused by stimulation of irritant receptors or C fibres by mucosal inflammation and oedema, ${ }^{34}$ or stimulation of stretch receptors related to the increase in end expiratory lung volume. ${ }^{5}$ Hypoxia may stimulate respiration in more severe exacerbations of asthma ${ }^{6}$ but hyperventilation is not dependent on hypoxia. ${ }^{5}$ Perception of changing airway resistance may contribute to the increased respiratory drive in asthma and is related to disease severity and frequency of exacerbations, mild stable asthmatics being more sensitive to change than those with severe brittle asthma. ${ }^{7}$ Psychological factors such as panic, anxiety, and depression ${ }^{8}$ may exacerbate bronchoconstriction by causing hyperventilation. There is conflicting information about the effect of airway hyperresponsiveness on respiratory control. However, acute asthma is often associated with anxiety, dehydration, infection, and other disturbances which may contribute to lowering of the $\mathrm{PCO}_{2}$. There is little information about the presence of hyperventilation in patients with chronic mild or moderate asthma in the absence of these possible acute confounding factors.

The aetiological factors which contribute to symptomatic hyperventilation or hyperventilation syndrome remain uncertain..$^{90}$ We have consistently argued that a major aetiological factor is very mild and often previously undiagnosed asthma which can lead to a vicious cycle of panic and disability. ${ }^{911}{ }^{12}$ For example, we have described a patient who presented with severe hyperventilation and tetany who was subsequently found to have asthma as the sole underlying aetiological factor for hyperventilation. ${ }^{11}$ In another study ${ }^{12}$ we investigated a group of patients presenting to our accident and emergency department with a primary diagnosis of hyperventilation. Approximately $80 \%$ had good evidence of underlying asthma which had been previously unrecognised in half of them. The association between symptomatic hyperventilation and asthma has been emphasised by others. For example, Demeter et $a l^{13}$ found an association
22 August 2000 .

Accepted for pubir

23 August 2000 
Table 1 Asthma history and medication of patients with asthma

\begin{tabular}{|c|c|c|c|c|c|c|c|}
\hline $\begin{array}{l}\text { Subject } \\
\text { (no) }\end{array}$ & Sex & $\begin{array}{l}\text { Age } \\
\text { (years) }\end{array}$ & $\begin{array}{l}\text { Time since } \\
\text { initial diagnosis } \\
\text { (years) }\end{array}$ & $\begin{array}{l}\text { Last hospital } \\
\text { admission (years) }\end{array}$ & $\begin{array}{l}\text { Time since last use of } \\
\text { inhaled or oral steroids }\end{array}$ & $\begin{array}{l}\text { Current } \\
\text { bronchodilator use }\end{array}$ & $\begin{array}{l}\text { Smoking } \\
\text { history }\end{array}$ \\
\hline 1 & M & 27 & 20 & $\mathrm{n}$ & $>2$ years & 2/week & $\mathrm{n}$ \\
\hline 2 & M & 25 & $>20$ & $\mathrm{n}$ & $>1$ year & $2 /$ week & $\mathrm{x}$ \\
\hline 3 & $\mathrm{~F}$ & 26 & $>20$ & $\mathrm{n}$ & $>4$ months & $1 /$ day & $\mathrm{x}$ \\
\hline 4 & $\mathrm{~F}$ & 35 & 28 & $\mathrm{n}$ & 1 year & 1/week & $\mathrm{n}$ \\
\hline 5 & $\mathrm{M}$ & 32 & 20 & $\mathrm{n}$ & childhood & $<1 /$ month & $\mathrm{c}$ \\
\hline 6 & $\mathrm{~F}$ & 22 & Childhood & $\mathrm{n}$ & $>1$ year & $<1 /$ month & $\mathrm{n}$ \\
\hline 7 & $\mathrm{~F}$ & 24 & Childhood & $\mathrm{n}$ & 6 months & $2 /$ day $^{\star}$ & $\mathrm{c}$ \\
\hline 8 & $\mathrm{~F}$ & 19 & Childhood & $\mathrm{n}$ & $\mathrm{n}$ & $<1 /$ month & c \\
\hline 9 & $\mathrm{~F}$ & 37 & 7 & $\mathrm{n}$ & $\mathrm{n}$ & 1/week & $\mathrm{x}$ \\
\hline 10 & M & 24 & 19 & $\mathrm{n}$ & 8 months & 2/day & $\mathrm{n}$ \\
\hline 11 & M & 29 & Childhood & $\mathrm{n}$ & $\mathrm{n}$ & $<1 /$ month & $\mathrm{n}$ \\
\hline 12 & $\mathrm{~F}$ & 32 & Childhood & $\mathrm{n}$ & $\mathrm{n}$ & $<1 /$ month & $\mathrm{n}$ \\
\hline 13 & $\mathrm{~F}$ & 24 & Childhood & $\mathrm{n}$ & $>5$ years & $1 /$ day & $\mathrm{x}$ \\
\hline 14 & M & 28 & 22 & $\mathrm{n}$ & $>15$ years & $<1 /$ month & $\mathrm{n}$ \\
\hline 15 & M & 30 & 23 & 13 & $>6$ years & 1/week & $\mathrm{x}$ \\
\hline 16 & M & 32 & 21 & $\mathrm{n}$ & $\mathrm{n}$ & $2 /$ month & $\mathrm{n}$ \\
\hline 17 & M & 24 & 18 & 4 & $>1$ year & $1 /$ week & $\mathrm{n}$ \\
\hline 18 & $\mathrm{~F}$ & 18 & 4 & $\mathrm{n}$ & 6 months & $2 /$ week & $\mathrm{n}$ \\
\hline 19 & M & 22 & 11 & $\mathrm{n}$ & $\mathrm{n}$ & $1 /$ week & $\mathrm{n}$ \\
\hline 20 & M & 25 & 15 & 10 & $>1$ year & $1 /$ day & $\mathrm{n}$ \\
\hline 21 & M & 34 & 2 & $\mathrm{n}$ & $>2$ years & 1/day* & $\mathrm{x}$ \\
\hline 22 & M & 25 & 13 & 13 & 7 years & $1 /$ month & $\mathrm{n}$ \\
\hline 23 & M & 20 & 11 & $\mathrm{n}$ & $\mathrm{n}$ & 2/week & $\mathrm{n}$ \\
\hline
\end{tabular}

$\mathrm{n}=$ never $; \mathrm{c}=$ current smoker $\mathrm{x}=$ ex-smoker

^Nocturnal symptoms $1-2 /$ week.

between asthma and hyperventilation syndrome in 36 out of 38 patients studied. However, the relationship between asthma and hyperventilation is complex and it can be difficult to distinguish true asthma from asthmatic symptoms induced by overbreathing. ${ }^{14}$ Nevertheless, in the study of hyperventilation in acute asthmatics by McFadden et al, a reduction in $\mathrm{FEV}_{1}$ of approximately $30 \%$ was associated with a reduction in $\mathrm{PaCO}_{2}$ to nearly half the normal level, ${ }^{1}$ well within the range of $1.86-3.86 \mathrm{kPa}(14-29 \mathrm{~mm} \mathrm{Hg})$ within which hypocapnia can cause symptoms in normal subjects. ${ }^{15}$ It would therefore be reasonable to propose that mild chronic asthma may be associated with even more marked hyperventilation and hypocapnia than has been described in acute asthma.

We therefore studied a group of patients with mild stable chronic asthma in comparison with a matched control group to determine (1) whether and to what extent hyperventilation is present in this group and (2) if present, whether arterial and/or its equivalent end tidal $\mathrm{PCO}_{2}\left(\mathrm{PETCO}_{2}\right)$ can be found to correlate with any aspect of airway function, airway hyperresponsiveness, airway mucosal inflammation, pattern of breathing, or psychiatric morbidity.

\section{Methods}

SUBJECTS

We recruited 23 subjects from our clinical trials unit with a clear history of asthma who were asymptomatic at the time of the study. They all had a history of a positive methacholine challenge test, normal lung function, and were atopic as confirmed by skin prick testing to common allergens. The subject details are shown in table 1 .

We also studied 17 control subjects with no history of respiratory or cardiovascular disorders including asthma, allergic rhinitis, exercise wheeze or limitation, or history of childhood chestiness or bronchitis as elicited by a detailed questionnaire. These subjects were matched for age, sex, and height with the asthmatic subjects. Lung function was normal and methacholine challenge was in the normal range $\left(\mathrm{PC}_{20}>8 \mathrm{mg} / \mathrm{ml}\right)$.

All the patients with asthma were young (age range 18-37 years) to reduce the possibility of unrelated disorders. A detailed clinical history was initially obtained. All had a long history of asthma with a time course of 20 years or more in 13 subjects and 10 years or more in a further seven. All subjects had a long history of intermittent bronchodilator use and could be divided into "very mild" with usage of bronchodilators less than once a month $(n=7)$, "mild" with usage once or twice a week $(\mathrm{n}=10)$, and "moderate" with usage once or twice a day $(n=6)$. These frequencies represent the average over the previous five years and do not necessarily reflect bronchodilator intake at the time of the study. Many of the subjects used their bronchodilators prophylactically before exercise rather than in response to actual symptoms. Two subjects in the "moderate" group reported occasional nocturnal symptoms but not within seven days of the study. No subject had taken oral or inhaled steroids within six months of the study and seven had never needed steroids of any form. None were taking any form of theophylline or any other medication. Thirteen percent of the patients and $12 \%$ of the control subjects were current smokers. A further $26 \%$ of patients and $18 \%$ of controls were ex-smokers. No subject had a history of any other disorders and no subject gave any history of paraesthesiae, cramps, or cerebral symptoms suggestive of hyperventilation.

The asthmatic patients were asymptomatic at the time of the study and for at least eight hours beforehand, and were not studied if they took, or felt the need to take, bronchodilators in the previous eight hours either at rest or during exercise, or if they had experienced any wheeze, shortness of breath, or chest discomfort over the same time period. These ques- 
tions were asked on a number of occasions and in a number of different ways during the course of the study to ensure truthful replies. Subjects were rejected if they reported any acute allergic or infective exacerbations of their asthma during the previous eight weeks. All subjects avoided caffeine for at least eight hours before the study, which was completed in one day for each subject.

Ethical permission was obtained from King's Healthcare Research ethics committee and subjects gave informed signed consent.

\section{PROTOCOL}

We performed the measurements described below in the following order: psychiatric questionnaires; ventilation and breathing pattern; arterial blood gas tensions; lung function; methacholine challenge; eosinophil count from induced sputum. All measurements were performed within a four hour period on one day. Care was taken to ensure that both groups were studied with an identical protocol in the order described. Skin prick testing for common allergens was performed on arrival.

\section{Psychiatric assessment}

Subjects completed a range of medical and psychological questionnaires. Psychiatric rating scales are established methods of screening for psychiatric disorder and a number of self-rating scales have been validated for depression and anxiety. They can be useful in differential diagnosis and have been used to screen for such disorders in chronic disease. The self-rating scales used in the present study were the Spielberger State Trait Anxienty Inventory $(\mathrm{STAI})^{16}$ and the Beck Depression Inventory (BDI). ${ }^{17}$

\section{Ventilation and pattern of breathing}

Ventilation was measured via a mouthpiece with a nose clip using a heated pneumotachograph (PK Morgan, Chatham, Kent, UK) with the subject in the sitting position. Subjects breathed quietly for 15 minutes and then five minutes of ventilation was recorded and averaged by a computer system (Systematica Ltd, UK) in which the pattern of breathing and $\mathrm{PETCO}_{2}$ were measured in real time. Minute ventilation $(\dot{\mathrm{V}})$, tidal volume $(\mathrm{VT})$, inspiratory time $\left(\mathrm{T}_{\mathrm{I}}\right)$, expiratory time $(\mathrm{TE})$, cycle duration (TT), mean inspiratory flow (VT/TI), and respiratory frequency (f) were recorded for each breath. Respired air was sampled continuously at the mouth and analysed for $\mathrm{PCO}_{2}$ by a P K Morgan capnograph 901-MK2 (Chatham, Kent, UK). PETCO $_{2}$ was measured by the computer system, which also measured the slope of the end tidal plateau and the timing of the inspiratory and expiratory phases of each breath from the $\mathrm{PCO}_{2}$ profile to allow removal of invalid breaths. A maximum of $10 \%$ of breaths were removed by such editing procedures. The mean of the remaining values provided the measures of $\mathrm{PETCO}_{2}$ in the subsequent analysis.

Arterial blood gas tensions

Arterial blood gas tensions were measured during ongoing ventilatory recording about two minutes after measurement of the respiratory pattern. Arterial blood was sampled from the non-dominant radial artery under local anaesthetic over at least 30 seconds. The sample was analysed immediately (AVL 995, AVL Medical Instruments AG, Schaffhausen, Switzerland) to give $\mathrm{PaCO}_{2}, \mathrm{PaO}_{2}, \mathrm{pH}, \mathrm{HCO}_{3}^{-}$, and base excess. $\mathrm{PETCO}_{2}$ was also measured during the arterial sampling $\left(\mathrm{PeTCO}_{2}(\mathrm{~s})\right)$ and provided a means of validating the end tidal measurements.

LUNG FUNCTION

Lung function variables measured included $\mathrm{FEV}_{1}$ and forced vital capacity (FVC) (Vitalograph, Buckingham, UK), peak expiratory flow rate (PEF) (Wright peak flow meter), carbon monoxide transfer factor (TLCO) and carbon monoxide transfer coefficient (KCO) ( $\mathrm{P}$ K Morgan Transfertest Model C), residual volume (RV) and total lung capacity (TLC) (P K Morgan body plethysmograph). All were expressed as percentage predicted for age and height.

BRONCHIAL REACTIVITY

Bronchial reactivity to methacholine was performed after lung function measurements (breath activated dosimeter, Mefar, Italy) and the concentration $(\mathrm{mg} / \mathrm{ml})$ that induced a fall in $\mathrm{FEV}_{1}$ of $20 \%$ from post saline inhalation $\left(\begin{array}{lll}\mathrm{PC}_{20} & \mathrm{FEV}_{1}\end{array}\right)$ was calculated according to a standard protocol. ${ }^{18}$ The maximum concentration of methacholine used was $32 \mathrm{mg} / \mathrm{ml}$. Criteria for entry into the asthmatic group were a $\mathrm{PC}_{20}$ of $<8 \mathrm{mg} / \mathrm{ml}$ and for the control group $>8 \mathrm{mg} / \mathrm{ml}$.

AIRWAY INFLAMMATION

Airway inflammation was assessed by measuring the percentage of eosinophils in induced sputum. Fifteen minutes after inhalation of salbutamol $200 \mu \mathrm{g}$ via metered dose inhaler, hypertonic saline at concentrations of $3 \%, 4 \%$, $5 \%$ were inhaled for seven minutes, each followed by spirometric tests for safety. ${ }^{19}$ The subjects were asked to rinse their mouth with water before and after each nebulisation. Sputum was expectorated every seven minutes and collected. Sputum plugs were selected and mixed with a volume of $0.1 \%$ dithioreitol (Sputolysin Reagent, Calbiochem, San Diego, USA) four times the sputum weight, vortexed, and left to homogenise on a bench rocker for 15 minutes at room temperature. ${ }^{20}$ Further dilution with the same volume of phosphate buffered saline (PBS) preceded sample filtration through a $48 \mu \mathrm{m}$ nylon gauze. The total cell count was adjusted with PBS to give a concentration of 200000 cells $/ \mathrm{ml}$. Aliquots of $100 \mu \mathrm{g}$ were applied to cytospin slides and stained using Wright's Giemsa (Sigma, Poole, UK) for differential cell counts which were performed blind on 400 non-squamous cells and eosinophils expressed as a percentage of the total cell count.

ANALYSIS OF DATA

Values for $\mathrm{PC}_{20} \mathrm{FEV}_{1}$ were log transformed to allow statistical analysis and presented as a 
Table 2 Comparison of selected variables between groups.

\begin{tabular}{|c|c|c|}
\hline & $\begin{array}{l}\text { Controls } \\
\text { Mean (SD) }\end{array}$ & $\begin{array}{l}\text { Patients } \\
\text { Mean (SD) }\end{array}$ \\
\hline VT (1) & $0.68(0.13)$ & $0.68(0.16)$ \\
\hline TI $(s)$ & $1.57(0.48)$ & $1.47(0.35)$ \\
\hline $\mathrm{TE}(\mathrm{s})$ & $2.43(1.02)$ & $2.26(0.55)$ \\
\hline $\mathrm{TT}(\mathrm{s})$ & $4.03(1.48)$ & $3.75(0.82)$ \\
\hline $\mathrm{f}(\mathrm{bpm})$ & $16.6(3.6)$ & $17.4(4.3)$ \\
\hline$\dot{\mathrm{V}}(1 / \mathrm{min})$ & $10.9(2.1)$ & $11.2(2.2)$ \\
\hline $\mathrm{PETCO}_{2}(\mathrm{kPa})$ & $5.28(0.40)$ & $4.89(0.47)^{\star \star}$ \\
\hline $\mathrm{PaCO}_{2}(\mathrm{kPa})$ & $5.27(0.38)$ & $4.96(0.43)^{\star}$ \\
\hline $\mathrm{a}-\mathrm{ET}(\mathrm{kPa})$ & $-0.13(0.24)$ & $0.04(0.20)^{\star \star}$ \\
\hline $\mathrm{PaO}_{2}(\mathrm{kPa})$ & $13.7(1.07)$ & $14.4(1.05)$ \\
\hline $\mathrm{pH}$ & $7.38(0.02)$ & $7.39(0.03)$ \\
\hline $\mathrm{HCO}_{3}^{-}(/ \mathrm{mmol})$ & $22.9(1.27)$ & $22.5(1.11)$ \\
\hline $\mathrm{BE}(/ \mathrm{mmol})$ & $-1.28(1.47)$ & $-1.71(1.47)$ \\
\hline $\mathrm{FEV}_{1}(\%$ pred $)$ & $101.7(16.5)$ & $97.6(11.6)$ \\
\hline $\mathrm{FEV}_{1} / \mathrm{VC}(\%$ pred $)$ & $76.1(20.8)$ & $76.2(7.4)$ \\
\hline PEF (\% pred) & $107.1(13.3)$ & $97.8(13.2)^{\star}$ \\
\hline TLCO (\% pred) & $122.2(15.8)$ & $128.8(15.7)$ \\
\hline Kco (\% pred) & $108.5(11.6)$ & $105.4(13.0)$ \\
\hline TLC (\% pred) & $95.6(12.1)$ & $102.6(10.2)$ \\
\hline RV (\% pred) & $86.6(22.9)$ & $108.3(31.5)^{\star}$ \\
\hline \multirow[t]{2}{*}{$\mathrm{PC}_{20}(\mathrm{GM} \mathrm{mg} / \mathrm{ml})$} & $\begin{array}{l}\mathrm{n}=6 ; 12.4(4.6) \\
\mathrm{n}=11 ;>32\end{array}$ & $1.65(1.56)$ \\
\hline & Median (range) & Median (range) \\
\hline Eosinophils (\%) & $0(0-3.2)$ & $3(0-27)^{\star \star}$ \\
\hline BDI & $2(0-9)$ & $2(0-10)$ \\
\hline Anxiety state & $23(20-48)$ & $31(21-58)^{\star}$ \\
\hline Anxiety trait & $28(20-50)$ & $36(21-58)$ \\
\hline
\end{tabular}

$V_{T}=$ tidal volume $; T_{I}=$ inspiratory time $; T_{E}=$ expiratory time $\mathrm{T} \mathrm{T}=$ cycle duration $; \mathrm{f}=$ respiratory frequency; $\dot{\mathrm{V}}=$ minute ventilation; $\mathrm{PETCO}_{2}=$ end tidal $\mathrm{PCO}_{2} ; \mathrm{PaCO}_{2}=$ arterial $\mathrm{PCO}_{2} ;$ a-ET $=$ difference between arterial and end tidal $\mathrm{PCO}_{2}, \mathrm{PaO}_{2}=$ arterial $\mathrm{PO}_{2} ; \mathrm{pH}=$ acidity of arterial blood; $\mathrm{HCO}_{3}{ }^{-}=$bicarbonate of arterial blood; $\mathrm{BE}=$ base excess of arterial blood; $\mathrm{FEV}_{1}=$ forced expired volume in one second; $\mathrm{FEV}_{1} / \mathrm{VC}=$ ratio of $\mathrm{FEV}_{1}$ to vital capacity PEF = peak expiratory flow; TLCO = single breath carbon monoxide gas transfer; $\mathrm{KCO}=$ gas transfer corrected for total lung volume; TLC = total lung capacity; RV = residual volume; $\mathrm{PC}_{20}=$ concentration of methacholine at $20 \%$ reduction of $\mathrm{FEV}_{1}$; BDI $=$ Beck Depression Inventory scores; Anxiety state and trait $=$ scores from Spielberger STAI.

${ }^{\star} \mathrm{p}<0.05,{ }^{\star \star} \mathrm{p}<0.01$ for comparison between groups.

geometric mean. All other data are presented as mean with standard deviation (SD) or standard error (SE). Ventilation, PETCO $_{2}$, blood gas tensions, and lung function variables were compared between groups using the Student's $t$ test. Mann-Whitney tests were used to compare $\mathrm{PC}_{20}$, eosinophil counts, and psychological scores. Parametric (Pearson) or nonparametric (Spearman rank correlation) regression analysis was used to study the relationship between ventilation or $\mathrm{PCO}_{2}$ and lung function, airway reactivity, airway inflammation, and psychological scores. A p value of $<0.05$ was considered to be significant except for the correlation matrix when a value of $<0.01$ was used.

Results

Twenty eight variables were measured; a comparison of the mean values of selected variables between the two groups is shown in table 2 . Representative variables were selected from each group to give a broad picture of the similarities and differences between the groups.

All lung function was in the normal range for both groups. There was no significant difference between the groups for $\mathrm{FEV}_{1}, \mathrm{FEV}_{1} / \mathrm{VC}$, or gas transfer. PEF was significantly lower in patients than in controls (97.8 (2.8)\% predicted vs 107.1 (3.2)\% predicted; $\mathrm{p}<0.05)$. RV was significantly higher in patients than in controls (108.3 (6.6)\% predicted vs 86.6 (5.5)\% predicted; $\mathrm{p}<0.02)$. The geometric mean $\mathrm{PC}_{20}$ $\mathrm{FEV}_{1}$ for the patients was $1.1 \mathrm{mg} / \mathrm{ml}$. Eleven
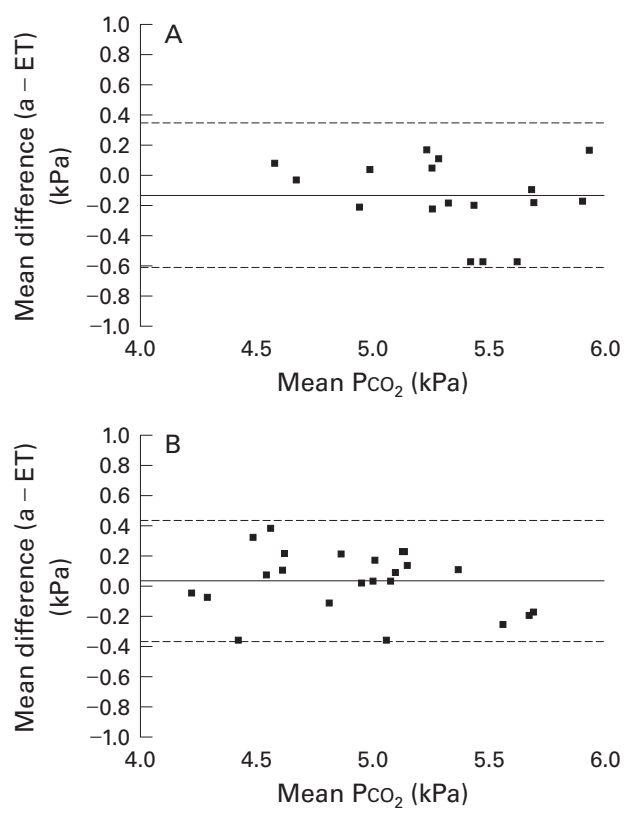

Figure 1 Bland and Altman plots for $(A)$ controls and (B) patients with asthma showing mean $\mathrm{PaCO}_{2}$ and $\mathrm{PETCO}_{2}$ values on the $x$ axis and the difference between the two on the $y$ axis. The mean values for individual subjects are shown; the solid horizontal lines represent the mean differences and the broken lines represent the limits of agreement.

control subjects had a $\mathrm{PC}_{20} \mathrm{FEV}_{1}$ of more than $32 \mathrm{mg} / \mathrm{ml}$, the highest concentration used; the geometric mean $\mathrm{PC}_{20} \mathrm{FEV}_{1}$ of the remaining six was $12.5 \mathrm{mg} / \mathrm{ml}$ (range $8.1-20.5 \mathrm{mg} / \mathrm{ml}$ ).

$\mathrm{PaCO}_{2}$ and all measures of $\mathrm{PETCO}_{2}$ were significantly lower in the patients than in the control group with mean (SE) $\mathrm{PaCO}_{2} 4.96$ $(0.09) \mathrm{kPa}$ and $5.27(0.09) \mathrm{kPa}$, respectively (mean difference $0.31 \mathrm{kPa}(95 \%$ CI 0.06 to 0.56), p<0.02). Equivalent values for $\mathrm{PeTCO}_{2}$ were $4.89(0.09) \mathrm{kPa}$ and $5.28(0.09) \mathrm{kPa}$, respectively (mean difference $0.39 \mathrm{kPa}(95 \%$ CI 0.12 to 0.66$), \mathrm{p}<0.01)$. Values of $\operatorname{PETCO}_{2}(\mathrm{~s})$ were very close to the arterial values with a correlation coefficient of $0.91(\mathrm{p}<0.001)$ and a mean difference of $0.04(0.04) \mathrm{kPa}$ in the patients, supporting the validity of end tidal measurements in these patients. This compares with a difference of $-0.13(0.05) \mathrm{kPa}$ in the controls. Bland and Altman plots with limits of agreement for the two groups are shown in fig $1 .^{21}$ The slope of the alveolar plateau was nonsignificantly greater in the patients with asthma than in the controls $(0.47(0.09) \mathrm{kPa} / \mathrm{s}$ vs 0.37 $(0.04) \mathrm{kPa} / \mathrm{s})$. There was a significant difference $(p<0.01)$ between male and female subjects for mean $\mathrm{PaCO}_{2}$ in the control group $(5.48(0.29) \mathrm{kPa}$ vs $4.95(0.28) \mathrm{kPa})$ but not in the patient group $(5.08(0.45) \mathrm{kPa}$ vs 4.83 $(0.33) \mathrm{kPa})$. The male/female ratio was similar in the two groups.

There was no significant difference between the two groups for other blood gas measurements and ventilatory variables. The reduced $\mathrm{PCO}_{2}$ in the patient group was associated with a slightly, but not significantly, greater ventilation and respiratory frequency with equivalent shortening of TI, TE, and TT (table 2). $\mathrm{PaO}_{2}$ was higher in the patients than in the control 
Table 3 Mean (SD) characteristics of patients according to bronchodilator use: very mild ( $\leqslant 1 /$ month), mild $(<1 /$ day $)$ and moderate $(\geqslant 1 /$ day $)$

\begin{tabular}{llll}
\hline & $\begin{array}{l}\text { Very mild } \\
(n=7)\end{array}$ & Mild $(n=10)$ & $\begin{array}{l}\text { Moderate } \\
(n=6)\end{array}$ \\
\hline $\mathrm{PETCO}_{2}(\mathrm{kPa})$ & $4.88(0.42)$ & $5.03(0.50)$ & $4.67(0.48)$ \\
$\mathrm{PaCO}_{2}(\mathrm{kPa})$ & $4.95(0.42)$ & $5.05(0.42)$ & $4.84(0.49)$ \\
$\mathrm{FEV}_{1}(\%$ pred $)$ & $101.6(9.0)$ & $93.7(9.2)$ & $99.6(17)$ \\
$\mathrm{PC}_{20}(\mathrm{GM})$ & $0.87(0.65)$ & $1.16(1.9)$ & $0.87(1.7)$ \\
Eosinophils (\%) & $1.9(1.4)$ & $7.7(9.2)$ & $4.9(3.8)$ \\
VT (1) & $0.68(0.13)$ & $0.69(0.21)$ & $0.66(0.08)$ \\
f (bpm) & $18.3(2.9$ & $16.8(5.8)$ & $17.2(2.9)$ \\
Anxiety state & $30.0(8.6)$ & $36.0(10.2)$ & $35.2(14.4)$ \\
Anxiety trait & $33.6(10.2)$ & $38.4(11.2)$ & $39.2(14.8)$ \\
BDI & $7(4.1)$ & $10(3.0)$ & $6(3.4)$ \\
& & &
\end{tabular}

See footonote to table 2 for definition of abbreviations. Only selected key variables are shown.

subjects, which was consistent with the reduced $\mathrm{PaCO}_{2}$. Base excess was negative in both groups.

Four control subjects produced poor sputum samples that could not be analysed. The sputum eosinophil count in the patients was significantly higher $(p<0.01)$ than in the controls (median 3.0 (range $0-27$ ) vs 0 (range $0-3.2), \mathrm{n}=13)$.

The patients had a significantly greater anxiety state score than the controls $(\mathrm{p}<0.02)$ despite the absence of clinical evidence of anxiety, but both scores were still within the normal range (25-35 for both state and trait). The BDI score for individuals was also within the normal range $(<10)$ and there was no significant difference between the two groups.

The patient group was divided into those with bronchodilator use of less than once a month, those with bronchodilator use of less than once a day, and those using bronchodilators more often than once a day. These groups were separately analysed for a limited but representative selection of variables (table 3 ). No significant difference was found for any variable between any of the groups, and there were no obvious trends as asthma worsened apart from a non-significantly higher anxiety score for the more severe subgroups.

Correlation coefficients for selected variables in the patients are shown in table 4 . There was a significant correlation between $\mathrm{PC}_{20}$ and $\mathrm{PaCO}_{2}(\mathrm{p}<0.01)$ and a slightly lower correlation $(\mathrm{p}<0.02)$ between $\mathrm{PC}_{20}$ and $\mathrm{PeTCO}_{2}$, but there were no equivalent correlations in the controls. Neither $\mathrm{PCO}_{2}$ nor $\mathrm{PC}_{20}$ correlated with any other measure of baseline airway function or inflammation. There was no relationship between the STAI scores and any measure of baseline lung function, airway hyperresponsiveness, or airway inflammation.

Eight of the 17 control subjects were positive to common allergens on skin prick testing. The atopic and non-atopic controls were analysed as a single group as no differences were found between any variables measured.

\section{Discussion}

This study illustrates the value of studying respiratory control and searching for small but significant changes in patients with very mild lung disease, rather than attempting to study more severe disease in which it is often difficult to control for extraneous factors. We have shown that uncomplicated mild and moderate chronic asthma is not associated with clinically significant hyperventilation, but we have demonstrated a small but statistically significant reduction in both $\mathrm{PaCO}_{2}$ and $\mathrm{PeTCO}_{2}$.

Although all of our asthmatic subjects were symptomatic at the time of the study and for at least eight hours previously, the reported severity of the asthma in the different subjects when considered over a long period of time varied from bronchodilator usage of less than once a month to usage on a daily basis, so we divided the patients into three subgroups on this basis corresponding roughly to very mild, mild, and moderate asthma. Unfortunately, this grouping was not able to distinguish between subjects who required bronchodilators for an actual attack of asthma and those who took their inhalers prophylactically-for example, before exercise. There was no consistent trend in any variable as severity increased apart from higher anxiety scores in the two more severe groups, and there was no significant difference in any variable between these three subgroups. There was an equivalent reduction in both $\mathrm{PaCO}_{2}$ and $\mathrm{PETCO}_{2}$ in each group.

No subject reported any symptoms suggestive of hypocapnia or hyperventilation, and we did not expect such symptoms as we specifically wished to study fit young subjects with only mild asthma uncomplicated by any clinical evidence of psychiatric or other problems. For the same reason, we did not perform any stress tests for hyperventilation ${ }^{9}$ although the results of these may have been of interest.

These results do not provide a ready explanation for the extreme symptomatic hyperventilation that we have observed in some

Table 4 Correlation coefficients between selected variables in patients with asthma

\begin{tabular}{|c|c|c|c|c|c|c|c|c|c|c|c|c|c|}
\hline & Trait & State & $B D I$ & Eos & $\log P C_{20}$ & $R V$ & $P E F$ & $F E V_{1}$ & $\mathrm{PaCO}_{2}$ & $\mathrm{PETCO}_{2}$ & $V_{T} / T_{I}$ & $\dot{V}$ & $f$ \\
\hline VT & -0.06 & 0.34 & -0.19 & 0.33 & -0.21 & 0.22 & -0.06 & -0.10 & -0.19 & 0.10 & $0.44 \dagger$ & 0.37 & $0.56^{\star}$ \\
\hline $\mathrm{f}$ & -0.31 & -0.31 & -0.24 & -0.13 & 0.13 & 0.03 & 0.20 & 0.19 & 0.17 & -0.22 & 0.25 & 0.50 & \\
\hline$\dot{\mathrm{V}}$ & 0.25 & 0.10 & 0.04 & 0.20 & -0.02 & 0.13 & 0.12 & 0.09 & -0.01 & -0.08 & $0.85^{\star}$ & & \\
\hline VT/TI & 0.24 & 0.06 & -0.12 & 0.04 & 0.00 & 0.28 & -0.12 & -0.10 & -0.07 & 0.06 & & & \\
\hline $\mathrm{PetCO}_{2}$ & -0.10 & 0.09 & 0.07 & -0.20 & $0.49 \dagger$ & 0.28 & -0.07 & 0.11 & 0.70 & & & & \\
\hline $\mathrm{PaCO}_{2}$ & -0.12 & -0.18 & 0.16 & -0.09 & $0.56^{\star}$ & 0.11 & 0.05 & 0.20 & & & & & \\
\hline $\mathrm{FEV}_{1}$ & 0.15 & 0.14 & -0.28 & -0.15 & 0.23 & 0.05 & $0.75^{\star}$ & & & & & & \\
\hline PEF & 0.31 & 0.10 & -0.29 & -0.03 & 0.15 & -0.13 & & & & & & & \\
\hline RV & 0.03 & 0.06 & -0.15 & 0.27 & 0.09 & & & & & & & & \\
\hline $\log \mathrm{PC}_{20}$ & 0.09 & -0.06 & -0.07 & -0.16 & & & & & & & & & \\
\hline Eos & -0.22 & -0.15 & -0.01 & & & & & & & & & & \\
\hline BDI & $0.65^{\star}$ & $0.59 \star$ & & & & & & & & & & & \\
\hline State & $0.70^{\star}$ & & & & & & & & & & & & \\
\hline
\end{tabular}

$\mathrm{VT} / \mathrm{T}_{\mathrm{I}}=$ mean inspiratory flow; eos = eosinophils; see footnote to table 2 for definition of other abbreviations. Significant coefficients $\left({ }^{\star} \mathrm{p}<0.01\right)$ shown in bold. $\mathrm{tp}<0.05$. 
of our patients, ${ }^{11}{ }^{12}$ and do not show that patients with mild chronic asthma have marked hypocapnia at rest as we had predicted. Other factors need to be sought to explain such a linkage in some patients. Nevertheless, in this study the range of $\mathrm{PaCO}_{2}$ in the patients with asthma was large, extending from 4.19 to $5.59 \mathrm{kPa}$ (31.4 to $41.9 \mathrm{~mm} \mathrm{Hg}$ ). Three of the 23 asthmatic subjects had a $\mathrm{PaCO}_{2}$ value of less than $4.27 \mathrm{kPa}(32 \mathrm{~mm} \mathrm{Hg})$, very close to the upper limit for induction of symptoms by voluntary hyperventilation in normal subjects, ${ }^{15}$ and seven had values below $4.67 \mathrm{kPa}$ (35 mm Hg), the lower limit of the accepted normal range for $\mathrm{PETCO}_{2}$. This contrasts with the control group in which only two subjects had $\mathrm{PaCO}_{2}$ values below $4.67 \mathrm{kPa}$ and these were only 0.05 and $0.01 \mathrm{kPa}$, respectively, below the lower limit of the normal range. These results are only applicable to subjects breathing on a mouthpiece which can itself influence breathing ${ }^{22}$ and which may have prevented more impressive hyperventilation when the subjects were uninstrumented outside the laboratory. We are currently restudying this using our new ambulatory capnograph in the same subject group during activities of daily living. ${ }^{23}$

It is possible that a key factor in determining whether asthma induces hyperventilation sufficient to induce symptoms is prior awareness of the diagnosis of asthma, and such lack of a previous diagnosis was present in the case study described by Gardner et $a l^{11}$ and in half of our patients presenting to the accident and emergency department with hyperventilation. ${ }^{12}$ About $80 \%$ of the patients in the latter study also had evidence of mild anxiety on questionnaires and it is reasonable to propose that dyspnoea and chest tightness which occurs suddenly and without an explanation is a potent source of anxiety and panic leading to hyperventilation, exacerbated by the tendency of patients when faced with unexplained symptoms to take large breaths, although demonstrable psychiatric morbidity was remarkably absent or minimal in many of the patients with symptomatic hyperventilation whom we have previously described. ${ }^{24}{ }^{25}$ In the present study the anxiety score was significantly higher in the asthma patients than in the controls but was still within the normal range. The relationship between asthma, hyperventilation, and anxiety requires further study.

This study shows a small but significant reduction in both $\mathrm{PaCO}_{2}$ and $\mathrm{PETCO}_{2}$ in patients with asthma and suggests that such a reduction is fundamental to the pathophysiology of asthma and is not an artefact or a paraphenomenon. Nevertheless, an explanation is required for our finding of a lower $\mathrm{PaCO}_{2}$ in the asthma patients without evidence of significant hyperventilation. It should first be emphasised that $\mathrm{PaCO}_{2}$ is dependent on alveolar, not inspired or expired, ventilation and we had no measurements of dead space or alveolar ventilation in our study. Although none of the patterning variables was significantly different, minute ventilation and respiratory frequency were slightly greater and both $\mathrm{T}_{\mathrm{I}}$ and $\mathrm{TE}_{\mathrm{E}}$ were shorter in the patients than in the controls; these differences may have become significant with a larger number of subjects. We do not believe that our finding of a lower arterial and end tidal $\mathrm{PCO}_{2}$ in the patients with asthma was related to methodological differences between the way in which the two groups were studied. Extreme care was taken to ensure that both groups were studied with exactly the same protocol and the methacholine challenge and induced sputum measurements were always performed after the measurements of $\mathrm{PCO}_{2}$ and thus could not have influenced the results.

In searching for other mechanisms which may have led to the increase in alveolar ventilation in the patients, it may be of significance that there was significant correlation of individual values of $\mathrm{PETCO}_{2}$ and $\mathrm{PaCO}_{2}$ with corresponding values of $\mathrm{PC}_{20}$ and it is conceivable that the mucosal inflammation and oedema associated with asthma resulted in a reduction in the dead space, contributing to an increase in the alveolar component of ventilation. However, dead space probably does not fall in asthma although it does fail to increase normally with inspiration. ${ }^{26} \mathrm{Nei}-$ ther group were hypoxic and this cannot provide an explanation. RV was significantly increased in the asthmatic patients and increased functional residual capacity (FRC) may be a factor in the hyperventilation associated with acute bronchospasm, ${ }^{527}$ probably mediated by stimulation of lung or chest wall mechanoreceptors, but it is difficult to understand how this could affect alveolar and not inspired ventilation. In this study reduction of $\mathrm{PCO}_{2}$ could not be attributed to any aspect of medication as the asthmatic subjects had not taken bronchodilators for at least eight hours before the study and none had taken steroids or other medication for many months.

Anxiety can induce hyperventilation and our asthmatic subjects had a significantly higher anxiety state score than the control group, with non-significantly higher scores in the more severe patients than in those with milder asthma. However, all psychiatric scores were within the normal range, and there was no suggestion of correlation between any of these scores and either $\mathrm{PaCO}_{2}$ or $\mathrm{PETCO}_{2}$. The significant correlation between STAI and BDI scores is of interest but is not surprising.

The highly significant correlation between $\mathrm{PC}_{20}$ and $\mathrm{PaCO}_{2}$ and the less significant $(p<0.05)$ correlation with PETCO $_{2}$ was striking. These are both independent variables, and this result should be contrasted with the complete lack of correlation with the markers of inflammation. While correlation matrices such as this can produce random significant values and the results should thus be interpreted with caution, it is reassuring that the only other significant correlations were those between related variables such as PEF and $\mathrm{FEV}_{1}, \dot{\mathrm{V}}$ and mean inspiratory flow, $\mathrm{f}$ and $\mathrm{VT}$, and the psychiatric scores against each other. The ventilatory responses to bronchoconstriction induced by bronchial challenge in the literature are vari$\mathrm{able}^{342829}$ and occur before the reduction in $\mathrm{FEV}_{1}^{30}$ and when bronchoconstriction is prevented by terbutaline inhalation, suggesting 
that increased respiratory drive may be induced by direct stimulation of vagal airway receptors. Inflammatory mediators may stimulate respiration by the same mechanism, but our results suggest that these did not play a part in the reduction of $\mathrm{PaCO}_{2}$ in our patients.

We have shown a relationship between arterial and end tidal $\mathrm{PaCO}_{2}$ and bronchial hyperresponsiveness but not with airway inflammation as measured by induced sputum eosinophil count. Both measures are widely used to assess the potential benefits of new asthma treatments $^{1920}$ but their relationship remains unclear. Allergen challenge induces an influx of eosinophils into the airways and a corresponding increase in airway hyperresponsiveness ${ }^{31}$ and may induce hyperventilation by stimulation of vagal afferents. ${ }^{4}$ Inflammatory mediators may contribute to the lowering of the threshold for stimulation of vagal afferent nerve endings, and a similar decrease in threshold may contribute to airway hyperresponsiveness in asthma. However, airway hyperresponsiveness is present even in the absence of inflammation $^{32}$ and persists after steroid therapy. In our study, in agreement with others, we found no relationship between airway hyperresponsiveness and airway inflammation in the asthmatic group.

This study confirms that end tidal measurements of $\mathrm{PCO}_{2}$ are accurate reflections of arterial $\mathrm{PCO}_{2}$ in mild and moderate asthma, the mean alveolar-arterial difference for the asthma patients being $0.04 \mathrm{kPa}$ compared with $0.13 \mathrm{kPa}$ for the controls, despite a small but expected increase in the slope of the alveolar plateau in the patients. The Bland and Altman plots (fig 1) show no consistent change in this difference across the range of values obtained, and show very similar plots for both controls and asthmatics. These results support another study showing a good association between arterial and end tidal values when $\mathrm{FEV}_{1}$ was over $80 \%$ predicted. ${ }^{33} \mathrm{We}$ would argue that end tidal measurements can be used with confidence in mild and moderate asthmatic patients as accurate reflections of arterial measurements.

In summary, we were not able to demonstrate clinically significant hyperventilation in our patients with mild and moderate chronic asthma, but these patients did have a statistically significant reduction in both arterial and end tidal $\mathrm{PCO}_{2}$ unrelated to lung function, airway inflammation, or measures of psychiatric abnormality, but associated with airway hyperresponsiveness. A small degree of hypocapnia may thus be intrinsic to the increase in airway smooth muscles contractility in asthma, but additional factors may also be involved in more severe acute exacerbations of asthma. This study will provide the basis for further studies both in mild asthmatics using noninvasive measurements by ambulatory techniques outside the laboratory, and in patients with severe hyperventilation associated with mild asthma.

The authors would like to thank the Wellcome Trust for financial support and the Guy's, King's and St Thomas' School of cial support and the Guy's, King's
Medicine for laboratory facilities.
1 McFadden ER, Lyons HA. Arterial blood gas tension in asthma. $N$ Engl f Med 1968;278:1027-32.

2 Lavietes MH. Ventilatory control in asthma. Clin Chest Med 1984;5:607-17.

3 Bleecker ER, Cotton DJ, Fischer SP, et al. The mechanism of rapid, shallow breathing after inhaling histamine aerosol in exercising dogs. Am Rev Respir Dis 1976;114:909-16.

4 Cotton DJ, Bleecker ER, Fischer SP, et al. Rapid, shallow breathing after Ascaris suum antigen inhalation: role of vagus nerves. F Appl Physiol 1977;42:101-6.

5 Kelsen SG, Prestel TF, Cherniack NS, et al. Comparison of the respiratory responses to external resistive loading and bronchoconstriction. $\mathcal{F}$ Clin Invest 1981;67:1761-8.

6 Cochrane GM, Prior JG, Wolff CB. Chronic stable asthma and the normal arterial pressure of carbon dioxide in hypoxia. BMF 1980;281:705-7.

7 Veen JC, Smits HH, Ravensberg AJ, et al. Impaired perception of dyspnea in patients with severe asthma. Relation to 1134-41.

8 Bass C, Kartsounis L, Lelliott P. Hyperventilation and its relationship to anxiety and panic. Integrative Psychiatry 987;5:274-91.

9 Gardner WN. Review: the pathophysiology of hyperventilation disorders. Chest 1996;109:516-34.

10 Folgering H. The hyperventilation syndrome. In: Altose $\mathrm{MD}$, Kawakami Y, eds. Control of breathing in health and disease. New York, Basel: Marcel Dekker, 1999:633-60.

11 Gardner WN, Bass C, Moxham J. Recurrent hyperventilation tetany due to mild asthma. Respir Med 1992;86:34951.

12 Saisch SGN, Wessely S, Gardner WN. Patients with acute hyperventilation presenting to an inner-city emergency hyperventilation presenting to an

13 Demeter SL, Cordasco EM. Hyperventilation syndrome and asthma. Am f Med 1986;81:989-94

14 Ringsberg KC, Akerlind I. Presence of hyperventilation in patients with asthma-like symptoms but negative asthma test responses: provocation with voluntary hyperventilation and mental stress. F Allergy Clin Immunol 1999;103:601-8.

15 Rafferty GF, Saisch SGN, Gardner WN. Relation of hypocapnic symptoms to rate of fall of end-tidal $\mathrm{PCO}_{2}$ in normal subjects. Respir Med 1992;86:335-40.

16 Spielberger CD, Gorsuch RL, Lushene RE. Manual for the state-trait anxiety inventory. Consultant Psychologists Press

17 Beck AT, Ward CH, Mendelson M. An inventory for measuring depression. Arch Gen Psychiatry 1961;4:561-71.

18 Juniper EF, Cockroft DW. Histamine and methacholine inhalation tests: tidal breathing method. Laboratory procedure and standardisation. Lund, Sweden: AB Draco, 1991.

19 Pin I, Gibson PG, Kolendowicz R, et al. Use of induced sputum cell counts to investigate airway inflammation in asthma. Thorax 1992;47:25-9.

20 Pizzichini MM, Popov TA, Efthimiadis A, et al. Spontaneous and induced sputum to measure indices of airway inflammation in asthma. Am $\mathcal{f}$ Respir Crit Care Med 996;154:866-9.

21 Bland MJ, Altman DG. Statistical methods for assessing agreement between two methods of clinical measurement. Lancet 1986;i:307-10.

22 Hirsch JA, Bishop B. Human breathing patterns on mouthpiece or face mask during air, $\mathrm{CO}_{2}$, or low $\mathrm{O}_{2} . \mathcal{F}$ Appl Physiol 1982;53:1281-90.

23 Osborne CA, Gardner WN, Varley JS. The range of end-tidal $\mathrm{PCO}_{2}$ measured noninvasively using an ambulatory capnograph in normal subjects. Eur Respir $\mathscr{f} 1997$; tory capnograph

24 Gardner WN, Meah MS, Bass C. Controlled study of respiratory responses during prolonged measurement in patients with chronic hyperventilation. Lancet 1986;ii:82630.

25 Bass C, Gardner WN. Respiratory and psychiatric abnormalities in chronic symptomatic hyperventilation. BMf 1985;290:1387-90.

26 Wilson JW, Li X, Pain MC. The lack of distensibility of asthmatic airways. Am Rev Respir Dis 1993;148:806-9.

27 Kassabian J, Miller KD, Lavietes MH. Respiratory center output and ventilatory timing in patients with acute airway (asthma) and alveolar (pneumonia) disease. Chest 1982;81: $536-43$

28 Stromberg NO, Gustafsson PM. Breathing pattern variability during bronchial histamine and methacholine challenges in asthmatics. Respir Med 1996;90:287-96.

29 Meessen NEL, Van Der Grinten CPM, Luijendijk SCM, et al. Breathing pattern during bronchial challenge in humans. Eur Respir f 1997;10:1059-63.

30 Fanelli A, Duranti R, Gorini M, et al. Histamine induced changes in breathing pattern may precede bronchoconstriction in selected patients with bronchial asthma. Thorax 1994;49:639-43

31 Brusasco V, Crimi E, Gianiorio P, et al. Allergen-induced increase in airway responsiveness and inflammation in mild asthma. I Appl Physiol 1990;69:2209-14.

32 Crimi E, Spanevello A, Neri M, et al. Dissociation between airway inflammation and airway hyperresponsiveness in allergic asthma. Am f Respir Crit Care Med 1998;157:4-9.

33 Osborne CA, Spurling KJ, Gardner WN. The relationship between arterial and end-tidal $\mathrm{PCO}_{2}$ in asthmatic patients. Eur Respir F 1999;14(Suppl 30):226s. 